\section{SIBIR Solicitations For Microscopy/Microanalysis Related Research \\ Eric B. Steel o}

National Institute of Standards and Technology

The Department of Commerce runs a Small Business Innovative Research Program to stimulate technological innovation in the private sector and strengthen the role of small business in meeting Federal research and development (R\&D) needs. A description of the program can be found at:

http://ts.nist.gov/ts/htdocs/200/204/98toc.htm

Two specific projects relating to microscopy and microanalysis areas where we are soliciting research proposals include:

8.10.6T SUBTOPIC: New Technology Detectors for Analytical X-ray Spectrometry

8.10.7T SUBTOPIC: Telepresence Electron Microscopy and Microanalysis Systems

While general topics, listed below, from the National Institute of Standards and Technology (NIST) include a wide variety of areas that may be of interest to some members.

8.6 Quality Assurance

8.7 Advanced Technology Program

8.8 Electronics and Electrical Engineering

8.9 Manufacturing Engineering

8.10 Chemical Science and Technology

8.11 Physics

8.12 Materials Science and Engineering

8.13 Building and Fire Research

8.14 Information Technology

\section{INTER/MICRO-98}

\section{Celebrates its $50 t h$ Amniversary}

INTER/MICRO-98, sponsored by McCrone Research Institute, will celebrate its 50th anniversary on August 10-13, 1998 at the Knickerbocker Hotel in Chicago.

This four-day symposium will give one the opportunity to come up-to-date on new instruments for, new techriques in, and new applications of microscopy. Sessions are offered in Hi-Tech microscopy, Instrumentation, General Interest, Forensic, Environmental, Art and Archeological topics.

An exhibit of new microscopical instrumentation and accessories will be exhibited.

Detailed information can be obtained from Nancy Daerr at McCrone Research Institute. Phone: (312)8427100, Fax: (312)842-1078, eMail: ndaerr@mcri.org
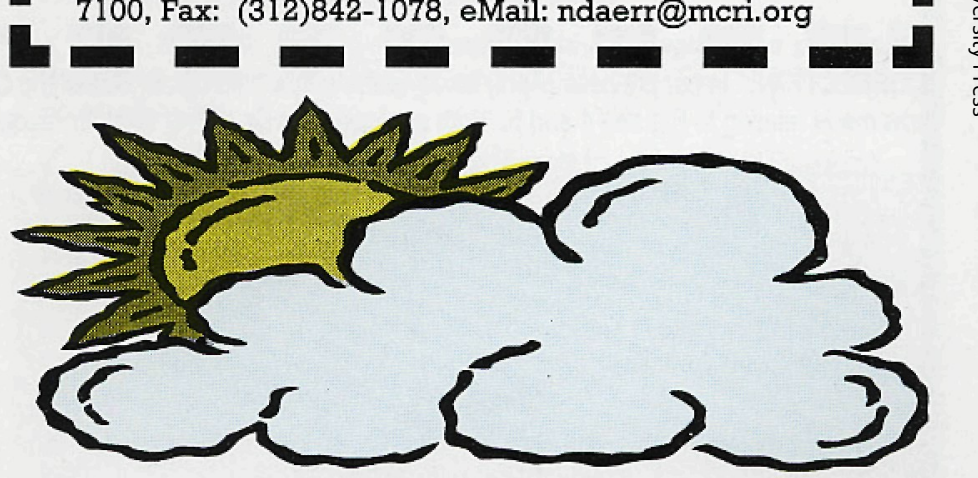

\title{
The Original Robinson Detector
}

Whether you use conventional, field emission, environmental SEMs, or defect review tools, the Robinson BSE Detector delivers unprecedented performance. It has more signal, less noise, and outstanding resolution.

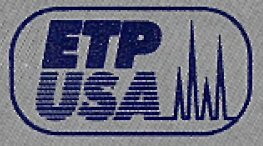

\section{ELECTRON DETECTORS INC.}

1650 Holmes Street, Bldg. C, Livermore, CA 94550 , USA.

Telephone: (800) 8 ETP USA, (925) 449-8534. Facsimile: (925) 449-8996

Email: info@etp-usa.com Web: http://www.etp-usa.com

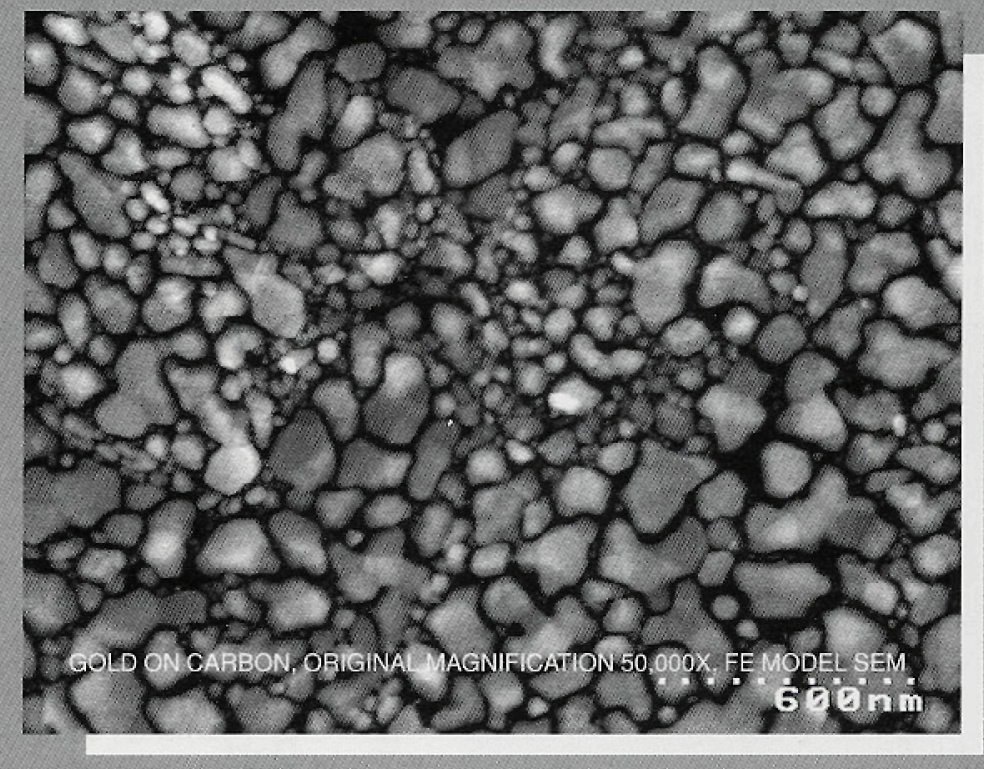

First

and

Still

the

Best!

When "Image" is everything... Only the Best Will Do! 